\title{
Extracellular Matrix Microenvironment in Glioma Progression
}

\author{
Marzenna Wiranowska ${ }^{1}$ and Mumtaz V. Rojiani² \\ ${ }^{1}$ Department of Pathology and Cell Biology \\ College of Medicine, University of South Florida, Tampa, Florida \\ ${ }^{2}$ Departments of Medicine and Pathology, GHSU Cancer Center Augusta, Georgia \\ USA
}

\section{Introduction}

Malignant gliomas are primary brain tumors, which are highly invasive but not known to metastasize outside the central nervous system (CNS). The median survival time of patients with glioma is only 6 months to 2 years depending on various patient, tumor and treatment parameters (Louis et al. 2007). The highly aggressive character of gliomas with glioblastoma multiforme (GBM) being the most aggressive subtype are characterized by their diffuse infiltration into the normal brain parenchyma and interaction with the extracellular matrix (ECM) components in the brain. Standard brain tumor therapies, which include surgery followed by chemotherapy and radiation are not effective in eradicating single glioma cells that migrated into the normal brain establishing new tumor foci. Glioma cells are locally invasive and when migrating through the ECM within several millimeters or centimeters from the main lesion they initiate recurrent tumors often distant to the primary lesion (Bolteus et al. 2001). The infiltrative path of glioma into the normal brain parenchyma involves the basement membrane of blood vessels and myelinated nerve fibers of white matter tracts (Rao 2003, Lefranc et al. 2005).

The pattern of glioma cell invasion is related to the unique composition of the cerebral ECM microenvironment, which is remodeled during invasion by activated matrix metalloproteinases (MMPs) (reviewed by Rojiani et al. 2011). In addition, new ECM molecules are secreted and receptor adhesion molecules are expressed by glioma promoting the glioma cell-ECM interaction and signaling. Some of the secreted ECM molecules such as tenascin- $\mathrm{C}$ are known to be associated with cell motility and angiogenesis which are both essential for tumor development. Another important microenvironment component affecting glioma development was found to be mechanical force determined by ECM rigidity. More rigid ECM promotes glioma migration and proliferation and lower rigidity of ECM (similar to that of normal brain) would have an opposite effect (Ulrich et al. 2009).

The recent sequencing data presented by the Cancer Genome Atlas Research Network (2008) revealed genomic abnormalities in GBM that relate to several signaling pathways such as Epidermal Growth Factor Receptor (EGFR) / Ras /PI3K known to be associated with ECM-related signaling (Ulrich et al. 2009). In addition, the recent integrated genomic analysis identified clinically relevant subtypes of GBM with its characteristic abnormalities 
in platelet derived growth factor receptor A (PDGFRA), isocitrate dehydrogenase 1 (IDH1), neurofibromin 1 (NF1), and confirmed EGFR mutations across all newly defined subtypes of GBM such as classical, proneural, neural and mesenchymal (Verhaak et al. 2010). The most recent studies by Holland (2011) in PDGF-driven mouse models of proneural GBMs with a focus on the biology, therapeutic response and the complexity of the microenvironment showed that some of the genes found in mice are predictive of the survival of patients with this proneural subtype of GBM. Interestingly, many of these genes are rather expressed in the stroma of the tumor than by the tumor cells themselves.

In this chapter, the most recent information pertaining to the glioma extracellular microenvironment and the possible biological targets within ECM for anti-glioma therapy will be reviewed.

\section{Extracellular matrix molecules in the normal brain}

In the central nervous system (CNS) approximately only $15-25 \%$ of the CNS volume is taken up by the extracellular space, while the majority of the CNS volume consists of cellular elements such as neurons, glia, astrocytic processes and blood vessels (Sykova 2002, Quirico-Santos et al. 2010). The components found within the extracellular space include various ions, metabolites, neurohormones, peptides and ECM molecules produced by neurons and glia. The ECM environment of the normal brain contains high levels of spacefilling carbohydrate molecules unbound to proteins such as the large glycosaminoglycan (GAG) hyaluronan (HA). HA binds to specific cell surface receptors such as cluster determinant 44 (CD44) adhesion molecule and receptor for hyaluronate mediated motility (RHAMM) regulating properties of ECM and tissue, e.g., proliferation, adhesion, motility etc. Protein-bound carbohydrate molecules, which are present in the normal brain at high levels, include sulfated proteoglycans such as chondroitin sulfate proteoglycans (CSPGs) and heparan sulfate proteoglycans (HSPGs). In addition, fibrous proteins associated with the basement membranes of the brain's vasculature include collagens, fibronectin, and laminin (Wiranowska and Plaas 2008). The levels of these fibrous proteins in the normal brain are low compared to the connective tissue outside the central nervous system (Bellail et al. 2004, Quirico-Santos et al. 2010). However, the ECM microenvironment of glioma differs from the normal brain and varies depending on the grade of glioma, e.g., with the highly aggressive GBM producing collagen, fibronectin or laminin (Mahesparan et al. 2003). Several classes of ECM molecules play an important role in the normal CNS development but have altered functions in glioma are reviewed below.

The main classes of ECM components in the normal brain are GAG hyaluronan (HA), also called hyaluronic acid, and proteoglycans (PGs), which consist of a core protein attached to GAG chain. HA plays multiple roles in providing an organization of the pericellular matrix. There is a high diversity of PGs due to various core proteins, and variations in GAG side chains. Two classes of transmembrane PGs, glypicans and syndecans, which contain heparan sulphate (HS) side chains called HSPGs are found at high levels in the CNS.

An important class of PGs are chondroitin sulfate PGs (CSPGs), which are expressed at high levels in the regions of the developing fetal brain and later in mature brain in astrocytes and neurons (Rao 2003, Quirico-Santos et al. 2010). CSPGs, and especially the subclass of lecticans, are one of the major families of HA binding matrix glycoproteins in the CNS. A second family of PGs that bind HA in the CNS are HA- and proteoglycan-link proteins (HAPLNs) also called "link proteins", which bind both HA and lecticans. The PGs called 
lecticans contain lectin and HA-binding domains and within that group there are molecules such as aggrecan, versican, neurocan, and brain enriched hyaluronic acid binding protein/brevican (BEHAB/brevican) that act as linkers to ECM components. They bind to $\mathrm{HA}$ as well as to cell-surface receptors regulating many processes within the CNS during development, e.g., cell motility, axonal navigation etc. (Sim et al. 2009). Some of these molecules such as versican are known to be produced by glial cells and neural stem cells (Abaskharoun et al. 2010). Another member of CSPGs is phosphocan, an astroglial proteoglycan that binds to neural cell adhesion molecules and tenascin-C. Neuroglial protein-2 (NG2), also a CSPG proteoglycan, which is known as a characteristic marker of oligodendrocyte progenitor cells and pericytes in developing vasculature, is expressed by many gliomas. The NG2 positive cells have been suggested to be the originating cells for glioma (Stallcup and Huang 2008).

Tenascins (C and R), a family of glycoproteins exist in the ECM as assemblies of several subunits expressed in zones of proliferation, migration, and morphogenesis and are known to play an important role in the developing CNS. For example, tenascin-C was found highly expressed in the subventricular zone and essential for neural stem cell development (reviewed by Wiranowska and Plaas 2008). Galectins (Gal), mannose- binding lectins, are glycan-binding proteins found inside and outside the cells. Gal-1 is highly represented in the CNS and takes part in the development of neural and non-neural networks and Gal-3 interacts with other neural tissue derived glycoproteins and is expressed by astrocytes and endothelial cells (Quirico-Santos et al. 2010). The role of many ECM components of the normal brain described above, are altered dramatically in glioma.

In the normal brain, the ECM complexes containing HA and PGs such as versican, brevican, neurocan, aggrecan, phosphacan and tenascin- $C$, tenascin- $R$, and link proteins form the ECM domains called perineuronal nets first described by Camillo Golgi in 1893. These perineuronal net aggregates enwrap the neuronal cell bodies and proximal dendrites of certain neurons and fill the space between neurons and glial processes. More recently, it was proposed that perineuronal nets within the brain are more heterogenous and include structures called "interstitial clefts" (Brightman 2002). As described by Brightman (Brightman 2002), interstitial clefts comprised of astrocytic walls, basal lamina and ECM molecules may vary in size, shape and content depending on the brain region. In addition, the size and the content of interstitial clefts was found to be different in the mature brain by being narrower with limited capacity for cell movement compared to that in the fetal brain. Here, in the fetal brain, the size and the content of interstitial clefts permit cell migration and outgrowth of neurites while in the mature brain cell migration in the interstitial clefts could only occur after enzymatic degradation of the ECM (Brightman 2002).

\subsection{Extracellular matrix in the brain as a cytokine and growth factor depot}

In the normal brain some regions are especially rich in ECM. These brain regions include subarachnoid space, supependymal packets, circumventricular organs (CVOs) supplied by fenestrated capillaries without blood-brain barrier (BBB), and perivascular space around arterioles and venules. These vessels are associated with stromal connective tissue space and lined by basal laminae containing heparan sulfate proteoglycans (HSPGs). HSPGs which are also components of ependymal, astroglial, and endothelial interfaces in the CNS (including interstitial clefts) have been suggested to serve as a storage site of growth factors and cytokines (Brightman and Kaya 2000). A large number of growth factors, for example, 
insulin-like growth factor (IGF), transforming growth factor-beta (TGF-beta), hepatocyte growth factor (HGF) were found to bind to HSPG (Folkman 1998). A similar observation was made for certain cytokines (reviewed by Wiranowska and Plaas 2008). It was suggested by Mercier et al. (Mercier et al. 2003) that cytokines and growth factors secreted by cells of connective tissue may accumulate in the basal lamina, interact with ECM proteins and affect biological processes including cytogenesis of stem cells in the CNS.

\subsection{Extracellular matrix stem cell niche in the brain}

In the CNS, the ability of normal stem cells to self-renew and to differentiate into specific cell types is controlled by the microenvironment of a CNS area in which these cells reside and which is called niche. Similarly, in other tissues and organs, stem cells are found in the protective microenvironment of niches, which are composed of ECM molecules and various differentiated cell types that release regulatory factors and provide direct contact with stem cells maintaining their quiescence. The CNS microenvironment of the neural stem cells (NSC) niche is also called vascular niche, because stem cells concentrate near blood vessels. The NSC niche consists of several ECM components, and includes the basal lamina and endothelial cells of vasculature (Doetsch 2003). These mature, differentiated vascular endothelial cells have an intimate association with stem cells and play a regulatory role in the NSC niche through secreted soluble factors. These factors were shown to promote activation of Notch, a neural precursor receptor, resulting in self-renewal of neural stem cells (Shen et al. 2004). In addition, the basement membrane (also known as basal lamina) contributes to the microenvironment and provides a substrate for stem cells' movement. The subventricular zone, a highly neurogenic area in the CNS, contains transmembrane HSPGs bound to the supependymal basal lamina located in proximity to the stem cells. As mentioned earlier (Section 2.1), HSPGs have the capacity to bind and to store a number of growth factors and cytokines thereby serving as a cytokine and growth factor depot. The growth factors and cytokines can diffuse quickly, and because of close proximity, they can reach high concentrations near the stem cells and regulate their development (Kearns et al. 2003). For example, EGF and basic fibroblast growth factor (bFGF) stored in the ECM of the subventricular zone can have a stimulatory effect on stem cells by enhancing their proliferation. The growth factors and cytokines can be stored in the ECM throughout life.

As mentioned earlier, one of ECM molecules, tenascin- $C$, is highly expressed in the subventricular zone and essential for neural stem cell development (Wiranowska and Plaas 2008). Tenascin-C plays a key role in the regulation of the developmental program of oligodendrocyte precursor cells (OPCs) and therefore confirming the importance of tenascin-C as an ECM component of the niche (Scadden 2006). Other ECM molecules, such as laminin and fibronectin, stimulate motility of stem/progenitor cells while CSPGs have an inhibitory effect (Kearns et al. 2003). It was also observed that upon activation of MMPs by proinflammatory cytokines, the neural progenitor cells were stimulated to migrate to the site of injury (Ben-Hur et al. 2006). In summary, many modulatory molecules were described within the ECM of the stem cell niche and, interestingly, many of them were found in glioma, but at higher levels than in the normal brain. In addition, not only the levels but also the functions of many of these molecules differ between the normal brain and glioma such as CSPGs, which are inhibitory for stem cells migration within the niche of the normal brain but stimulatory for glioma cell migration (Kearns et al. 2003, Sim et al. 2009). 


\section{Extracellular matrix in glioma}

\subsection{Role of ECM and MMP molecules in vasculogenic mimicry in glioma: Historical perspective}

It was observed previously by Maniotis et al. (Maniotis et al. 1999) that blood vessels of highly aggressive tumors such as uveal melanoma originated from tumor cells, rather than from endothelial cells as it was originally expected. This phenomenon named vasculogenic mimicry (VM) was reported later also for other tumors including glioma (Yue and Chen 2005). Although the mechanism of VM could not be explained at that time, many studies evaluated MMPs and ECM interactions in search for clues. It was suggested that several components of the tumor microenvironment may be contributing to the development of VM. For example, consideration was given to MMPs' cleavage of laminin, VE-cadherinpromoted adherence of newly formed vascular channels to tumor cells, and dedifferentiation of tumor cells (Zhang et al. 2007). Three main factors were suspected to play a role in VM: 1) plasticity of malignant tumor cells, 2) remodeling of the ECM by MMPs secreted by tumor cells to obtain space for VM, and 3) the connection of newly formed VM channels with existing blood vessels to acquire blood from the host (Zhang et al. 2007). It was proposed by Maniotis et al. (Maniotis et al. 1999) that the level of the VM channel formation was directly proportional to the level of tumor aggressiveness and influenced by interstitial fluid pressure (IFP), a microenviromental factor known to affect angiogenesis. Tumors that proliferate rapidly have high IFP and compromised blood circulation. In addition, there is a limited blood supply from the host due to decreased endothelial cell sprouting and decreased formation of endothelium-lined blood vessels. Therefore, tumor cells that form VM channels obtain a sufficient blood supply to sustain tumor growth. It was observed that the blood vessels formed as a result of VM had a different structure than normal endothelial-lined blood vessels. VM channels were found to be lined by highly aggressive and poorly differentiated tumor cells that could degrade the base membrane of blood vessels by releasing proteases and migrate into the normal tissue. Recent data (Inoue et al. 2010) support this observation by showing that GBM cancer stem cells express MMP13 responsible for invasion and migration of these cells.

Anti-vascular and anti-angiogenic therapies that used molecules such as angiostatin or endostatin that target endothelial cells, showed no effect on tumors with VM. To overcome the lack of understanding of the molecular mechanisms underlying VM, several in vitro studies were initiated in search of new therapeutic approaches based on the concept of ECM involvement in VM formation. For example, laminin was targeted in vitro showing that an anti-laminin antibody was able to inhibit VM channel formation by tumor cells (Sanz et al. 2003). Other in vitro studies targeted and inhibited MMP-2 and MMP-9 involved in VM by using doxcyline (Zhang et al. 2007). Also, it was shown that the Cox-2 inhibitor, celecoxib, inhibited in vitro VM formation in a dose-dependent manner (Basu et al. 2005). Although, these results were only obtained in vitro, there may be a recent indirect in vivo confirmation. Interestingly, recent in vivo studies using a glioma mouse model, showed that non-steroidal anti-inflammatory drugs (NSAID) such as Cox-2 inhibitors suppress gliomagenesis (Fujita et al. 2011). Although the primary conclusion of this study was that gliomagenesis was suppressed due to inhibition of prostaglandin E2-dependent accumulation of myeloid derived suppressor cells in the tumor microenvironment, a secondary effect of Cox-2 inhibitors on VM may be involved as addressed in section 6.2.2. 


\subsection{Microenvironment of glioma stem cell vascular niche: New theory of vascular mimicry}

Recently, a new concept of cancer progenitor cells, also known as cancer-initiating cells or cancer stem cells (CSCs), was proposed. These self-renewing, multipotent CSCs are highly tumorigenic and resistant to conventional therapies (Lakka and Rao 2008). Glioblastoma CSCs resemble the normal NSC and express the markers Nestin+/ CD133+ found in the neural stem cell population. Also, glioma CSCs, similar to NSCs, concentrate around blood vessels in the vascular niches with easy access to nutrients, signaling molecules, and the vasculature itself as a substrate for migration (Calabrese et al. 2007, Denysenko et al. 2010). However, CSCs differ from NSCs in their distribution in the brain and their capacity to proliferate. For example, the normal NSCs, which proliferate at a low rate are found only in specific CNS regions such as hippocampus and subventricular zone. In contrast, highly proliferative glioma CSCs can be found distributed across in all regions of cerebrum and cerebellum within the tumors. It was proposed that the main difference between the normal NSCs and glioma CSCs may be the way in which these cells are modulated by the microenvironment of the vasculature within the niche (Calabrese et al. 2007). The vascular niche in brain tumors is abnormal in such that it contributes to the propagation of CSCs thereby enhancing tumor growth. Furthermore, the endothelial cells from this abnormal vascular niche can interact with brain tumor CSCs, as shown in vitro, providing certain extracellular regulatory factors and maintaining the self-renewal capability and undifferentiated state of these cells (Calabrese et al. 2007). In that way the glioma vasculature establishes a microenvironment of the niche in which CSCs can transmit and receive signals from the ECM. For example, it was shown that upon stimulation of CSCs by ECM of the vascular niche, the CSCs can secrete vascular endothelial growth factor (VEGF) promoting angiogenesis and thereby enhancing tumor growth (Bao et al. 2006). In addition, the vascular niche was shown to interfere with radiation and chemotherapy by shielding the CSCs and contributing to the resistance to treatments (Denysenko et al. 2010). It was also suggested that the microenvironment of the niche may play a role in tumor initiation based on the observation that non-tumorigenic cell populations may become tumorigenic depending on a certain microenvironment (Rosen and Jordan 2009). Recent reports show that GBM stem cells have similar capabilities as the normal NSCs and undergo differentiation into endothelial cells forming the majority of new blood vessels in gliomas (El Hallani et al. 2010, Ricci-Vitiani et al. 2010, Wang et al. 2010). Blocking VEGF or silencing VEGF receptor 2 inhibits the maturation of tumor endothelial progenitors into endothelium but does not stop the differentiation of CSCs (CD133+ cells) into endothelial cells. However, silencing of Notch (neural precursor receptor as mentioned in section 2.2) blocks the transition of CSCs (CD133+ cells) into endothelial progenitors (Wang et al. 2010). Further studies of the microenvironmental components within the brain tumor vascular niche could lead to new therapeutic targets for treatments of glioma.

\subsection{Extracellular matrix and mechanical rigidity in glioma}

There are anatomic variations in stiffness in the normal brain parenchyma (Elkin et al. 2007) with basement membrane of blood vessels and the myelinated fiber tracts of white matter exhibiting a higher mechanical rigidity (Lefranc et al. 2005) and both serving as an infiltrative path for glioma invasion (Rao 2003, Ulrich et al. 2009, Kumar 2009). It was first observed in vitro that directed migration of fibroblasts occurs from soft to stiff areas of the ECM, a phenomenon named mechanotaxis (Lo et al. 2000). A similar observation was made 
for glioblastoma where changes in ECM rigidity can both increase and decrease cell motility and the extent of the effect was cell-type dependent (Thomas and DiMilla 2000). It was found that high ECM stiffness enhanced the expression of contractility-mediating proteins such as Rho (Paszek et al. 2005). ECM components have been found to be the main regulators of cell motility in the brain. For example, previous studies showed a stimulatory effect of ECM proteins such as fibronectin, collagen, laminin and others on glioma cell migration (Mahesparan et al. 2003). Ulrich et al. (Ulrich et al. 2009) had shown that glioma cells cultured on fibronectin-coated polymeric ECM with varied but defined mechanical rigidity exhibited altered cell morphology and cytoskeletal organization. These authors showed that glioma cells cultured on softer substrates showed a decreased spreading area, disappearing stress fibers and focal adhesions. Interestingly, all evaluated glioma cell lines cultured on the softest substrates were rounded but viable with cortical rings of F-actin and punctuate vinculin-positive focal complexes, and with no indication of apoptosis (Ulrich et al. 2009). The rigidity of the soft substrates used in that study was comparable to the ECM rigidity of normal brain parenchyma while an increased stiffness was characteristic for glioma and its surrounding stroma.

In addition, it was shown that increasing ECM rigidity resulted in increased cell spreading, motility and proliferation. It was suggested previously that glioma cells actively remodel their microenvironment changing it from normal brain ECM to rigid tumor-like ECM (Nakada et al. 2007). Therefore, it was suggested that glioma cells modify their ECM through proteolytic degradation of the normal brain matrix and secretion of new ECM components, thereby providing for a stiffer and more rigid microenvironment which in turn sends mechanobiological signals that support glioma cell invasion (Ulrich et al. 2009). This was observed previously also for invading breast cancer cells (Provenzano et al. 2008). By targeting either the signaling pathways for mechanotaxis or mechanical remodeling itself, new therapeutic approaches could be developed for the treatment of glioma which would affect glioma invasion and proliferation.

\subsection{Extracellular matrix molecules in glioma}

\subsubsection{Glycosaminoglycan hyaluronan and CD44 adhesion molecule}

Glioma cells constitutively produce $\mathrm{HA}$ and its production is increased during cell proliferation (Wiranowska and Naidu 1994, Wiranowska et al. 2010) promoting glioma invasion (Park et al. 2008). HA is synthesized at the plasma membrane by HA-synthases and the synthesis can be enhanced by various growth factors, e.g., epidermal growth factor (Knudson and Knudson 1993) Interestingly, the content of HA in glioma resembles that of embryonic brain cells (Delpech et al. 1993). HA binds to the HA-binding proteins called hyaladherins which include the CD44 surface receptor. CD44 is a transmembrane glycoprotein expressed by many cell types and by glioma. CD44 serves as a surface receptor for ECM molecules such as HA and CSPGs (Ranuncolo et al. 2002).

CD44 receptor is overexpressed in glioma cells in vitro (Wiranowska et al. 2000, Yu et al. 2010) and found in vivo at the leading edge of glioma at the brain-tumor interface (Wiranowska et al. 2006). The HA-CD44 interaction and CD44 shedding from the cell surface were found to be associated with glioma cell motility, migration, and infiltration into the normal brain parenchyma (Annabi et al. 2005). These authors also described that CD44 shedding was mediated by HA and accompanied by up-regulation of MT1-MMP expression. 
After binding to the CD44 receptor, HA can be endocytosed, transported into lysosomes and degraded by hyaluronidases into small oligosaccharides shown to have glioma - stimulatory activity (Novak et al. 1999). It was previously reported that while small HA fragments were found in the tumor tissues, native HA of high molecular mass was found in the normal and benign tissue (Rooney et al. 1995). Both the high levels of full length polymeric HA and its low molecular weight degradation products, HA fragments, known as oligosaccharides support glioma growth (Novak et al. 1999). The HA oligosaccharides, e.g., hexamer oligoHA-6 (HA-6) or decamer oligoHA-10 (HA-10) are able to displace full length HA via competition for CD44 receptor binding. HA can be effectively displaced by HA decasaccharides, such as HA-10, but not by HA oligosaccharides that are shorter than 10-mer (Tammi et al. 1998). It was observed that full length, large size HA had an antiangiogenic property, whereas smaller oligosaccharides after degradation (3-10 disaccharide units) were no longer anti-angiogenic (Deed et al. 1997). We found that small size oligosaccharide, decamer HA-10, exogenously added to the cell culture stimulated HA production by glioma cells (Wiranowska et al. 2010), as previously described for normal human fibroblasts (Luke and Prehm 1999). These authors found that displacement of nascent HA from the receptors by HA oligosaccharides led to stimulation of HA synthesis (Luke and Prehm 1999). Further studies of HA and the role of HA-CD44 interaction in glioma growth and invasiveness may provide new therapeutic targets for the treatment of glioma. Recent therapeutic approaches targeting HA-CD44 interaction are discussed in the Section 5.2.

\subsubsection{Chondroitin sulfate proteoglycans (CSPGs)}

CSPGs are expressed at elevated levels in the developing brain (as described in sections: 2 \& 2.2). In the normal brain, they are known for their inhibitory effect on stem cell migration (section 2.2). In glioma however, CSPGs are upregulated and stimulate glioma cell migration (Kearns et al. 2003, Sim et al. 2009). The two members of the CSPG subclass of lecticans (described in section 2) such as versican and BEHAB/brevican are expressed at a higher level in glioma than in the normal brain tissue. In addition, it was reported that the $\mathrm{VO} / \mathrm{VI}$ versican isoform expressed by migratory glioma cells interacts with surface receptors e.g., EGFR activating the ERK signaling pathway involved in tumor promotion (Ricciardelli et al. 2009). In addition, versican and brevican can form complexes with mesenchymal matrix proteins found in the ECM of glioma, but not in the ECM of the normal brain (Sim et al. 2009). Gliomas of various grades, e.g., astrocytoma and GBM secrete high levels of BEHAB/brevican. The CSPG lectican has an N-terminal HA-binding domain that interacts with fibronectin, thereby further stimulating glioma progression (Viapiano and Matthews 2006). Several other ECM molecules such as HA, CD44, tenascin and transforming growth factor beta2 (TGFbeta2) also interact with versican and promote brain tumor cell invasion. Recently, the link proteins HAPLN4 and HAPLN2 were shown to be reduced in malignant gliomas and it was suggested that this reduction may be associated with matrix remodeling by glioma. Therefore, in contrast to the normal brain tissue where CSPGs lecticans associated to HAPLNs serve as inhibitors of cell motility, in glioma this stabilizing role of link proteins may be reduced or lost resulting in proinvasive activity of CSPGs in glioma (Sim et al. 2009).

Another member of CSPGs family, neuroglial protein 2 (NG2), is also overexpressed in glioma (Schrappe et al. 1991, Wiranowska et al. 2006). NG2 was first found to be expressed 
by oligodendrocyte progenitor cells (section 2). NG2 expressed by glioma cells has a strong association with ECM ligands such as collagen VI and cellular ligands such as CD44. It has been implicated in the invasive behavior of glioma and found to be expressed in vitro and in vivo by highly migratory glioma cells while not found in non migratory cells (Lin et al. 1996, Galli et al. 2004, Wiranowska et al. 2006, Stallcup and Huang 2008). NG2 is not only expressed by oligodendrocyte progenitor cells and glioma cells but also by pericytes, which are associated with microvasculature and may play a role in the development of glioma vasculature (Stallcup and Huang 2008). Therefore, NG2 may be considered as one of the main CSPGs involved in glioma progression.

\subsubsection{Vasculature-associated ECM molecules expressed by gliomas}

The basement membrane of the cerebral vasculature contains collagens (type IV and V), fibronectin, laminin, vitronectin and HSPGs such as glypicans and syndecans. Some HSPGs, e.g., syndecan-2 were reported to be increased in brain tumors (Theocharis et al. 2010). Laminin, collagen and fibronectin were also shown to be expressed by normal brain tissue bordering with glioma cells in spheroids (Knott et al. 1998). In addition, some of these molecules are also expressed by cells of highly aggressive gliomas. For example, it was found that fibronectin was expressed by GBM in vitro and in gliomesenchymal junctions in tumors and their blood vessels (Rao 2003). Another molecule, vitronectin, was found to be expressed in late stage GBM while it was absent in normal brain and early stage of glioma (Yamamoto et al. 1994). Laminins, which were found in blood vessels and in the glial limitants externa in glioma, were also shown to be expressed by human glioma cells positive for glial fibrillary astrocytic protein (GFAP) (Tysnes et al. 1999). An active site on laminin which was capable of binding to CD44 was identified (Hibino et al. 2004). In addition, Ljubimova et al. (Ljubimova et al. 2004) found that highly invasive GBMs overexpressed laminin- 8 , a member of the subset of laminins characterized by containing the alpha4 chain. Moreover, these authors also found that laminin- 8 not only facilitated tumor invasion in vitro, but was involved in tumor regrowth after completion of a therapy. On the contrary, a different isoform, laminin-9, was found in lower grade gliomas, astrocytomas, and at low levels in benign brain tumors and in normal brain tissue. Therefore, many of these ECM molecules originally known to be associated with vasculature and now found at various levels expressed by glioma cells could be considered as biomarkers of glioma progression.

Tenascin $-C$, a proteoglycan synthesized by glial and neural crest cells is highly expressed in the subventricular zone and essential for the development of neural stem cells (as described in sections $2 \& 2.2$ ). Tenascin-C, which is believed to be produced by endothelial cells, was found around blood vessels in astrocytoma and its expression correlated with angiogenesis and tumor progression from grade II to grade III (Zagzag et al. 1995, QuiricoSantos et al. 2010). Tenascin-C was found overexpressed in invasive glioma both in vitro and in vivo (Mahesparan et al. 2003) thus confirming its significance as an ECM molecule in glioma pathology. Also, galectins are upregulated in glioma and shown to be involved in glioma cell migration and angiogenesis. While high levels of Gal-1 are correlated with aggressiveness of many tumors, the expression of Gal-3 by astrocytes and endothelial cells can be used diagnostically to differentiate GBM from other, less malignant types of glioma (Quirico-Santos et al. 2010). The schematic representation of ECM glioma microenvironment and the summary of representative ECM molecules and their functional significance are shown in Figure 1 and Table1. 


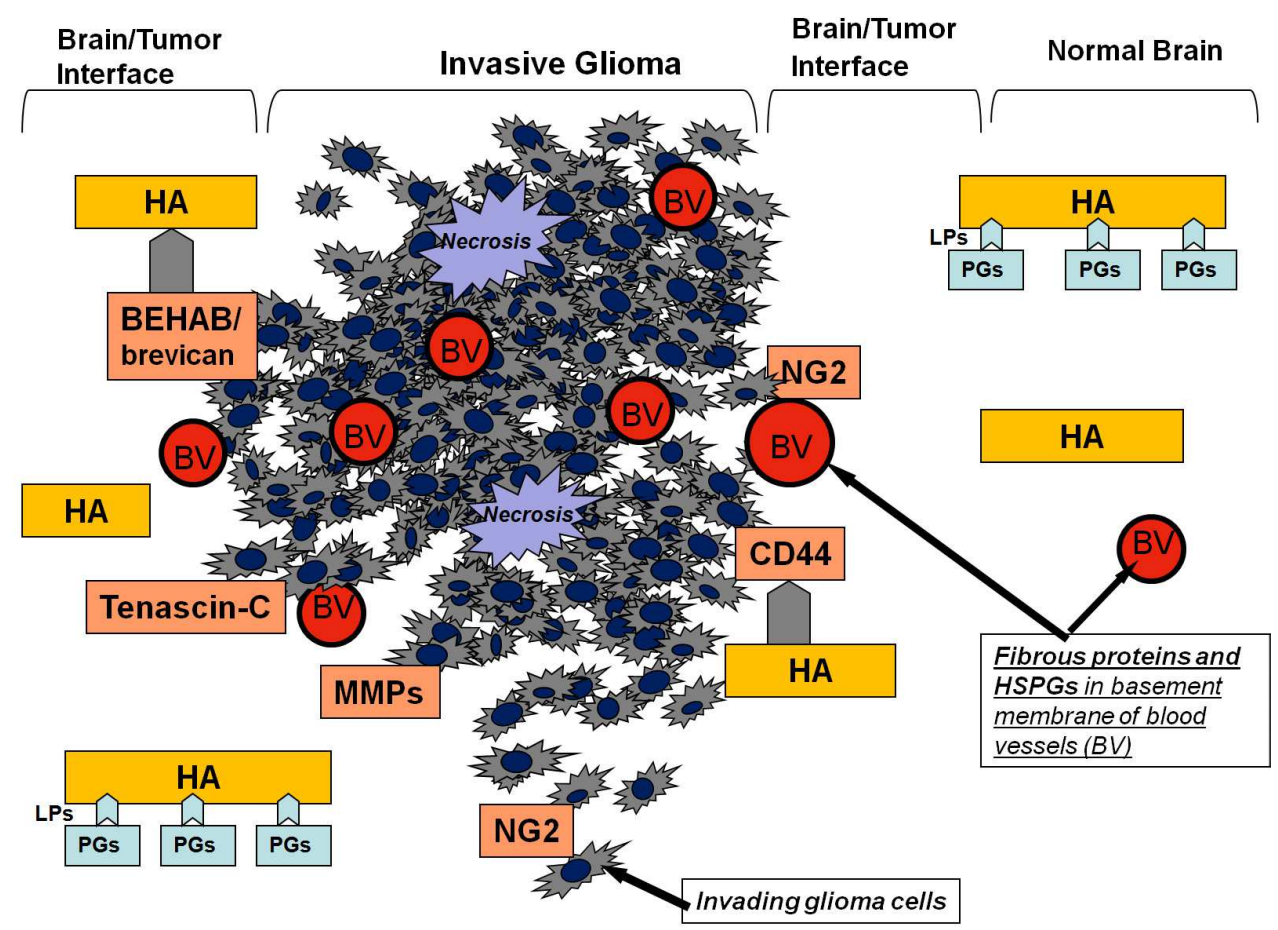

Fig. 1. Schematic representation of the extracellular matrix (ECM) microenvironment of invasive glioma with necrotic centers and associated brain parenchyma. Hyaluronic acid (HA), a long space-filling molecule composed of a carbohydrate chain is shown either unbound or bound to proteoglycans (PGs) via link proteins (LPs) or bound to CD44 receptor. Also shown are two glioma associated ECM molecules (both chondroitin sulfate proteoglycans): brain enriched hyaluronic acid binding protein/brevican (BEHAB/brevican) and neuroglial protein-2 (NG2) with the latter expressed by glioma cells and pericytes of blood vessels. In addition, glycoprotein tenascin-C, and matrix metalloproteinases (MMPs) are shown. Blood vessels (BV) shown in the glioma and the associated brain parenchyma contain fibrous proteins such as collagens, laminins etc. and heparan sulfate proteoglycans (HSPGs) associated with the BV basement membrane.

\section{Proteases, Matrix Metalloproteinases (MMPs), Their Inhibitors (TIMPS) and remodeling of ECM in glioma}

Matrix Metalloproteinases (MMPs) are a class of enzymes known to be involved in normal tissue remodeling, but also produced by glioma cells (Wiranowska et al. 2000) and involved in modification of glioma ECM. In the past, MMPs were considered a potential target for anti-cancer therapies. The result of ECM degradation by MMPs is the release and diffusion of cytokines and growth factors stored in the ECM with subsequent further activation of MMPs by these factors (Wiranowska and Plaas 2008). Since upregulation of MMPs was traditionally associated with inflammation and cancer progression, MMPs were considered 
a logical target for anti-cancer therapy. Supporting evidence was generated using transgenic mouse models overexpressing MMPs (Ha et al. 2001).

\begin{tabular}{|c|c|c|c|}
\hline \multirow[t]{2}{*}{ Molecules } & \multicolumn{2}{|c|}{ Location } & \multirow[t]{2}{*}{ Function } \\
\hline & Brain & Glioma & \\
\hline $\begin{array}{l}\text { Glycosaminoglycans (GAGs): } \\
\text {-Hyaluronan (HA) } \\
\text {-Proteoglycans (PG)s: } \\
\text {. Chondroitin sulfate PGs(CSPGs) } \\
\text {.. lecticans: } \\
\text { aggrecan } \\
\text { neurocan } \\
\text { versican } \\
\text { BEHAB/brevican } \\
\text {.. NG2 } \\
\text {. Link proteins (LPs)/ HAPLNs } \\
\text {. Heparan sulfate PGs (HSPGs) } \\
\text { (glypicans, syndecans: syn.) }\end{array}$ & $\begin{array}{l}+ \\
+ \\
+ \\
+ \\
+ \\
+ \\
+ \\
+ \\
+\end{array}$ & $\begin{array}{c}+++ \\
? \\
++ \\
+++ \\
+++ \\
+++ \\
\\
+1- \\
+ \\
++ \text { (syn.-2) }\end{array}$ & $\begin{array}{l}\text { HA: space filling molecule, binds to cell surface receptors: CD44 and } \\
\text { RHAMM; regulation of ECM; regulates cell proliferation, adhesion, } \\
\text { motility. } \\
\text { PGs: HA binding proteins } \\
\text { CSPGs: high levels in the developing fetal brain and glioma } \\
\text { Lecticans: aggrecan (neurons), neurocan (neurons \& glia), versican } \\
\text { (glia), brevican (glia \& neurons); bind to HA and cell surface } \\
\text { receptors, regulate cell motility, axonal navigation; enhance } \\
\text { migration of glioma cells; inhibit normal brain stem cell migration. } \\
\text { NG2: expressed by CNS progenitor, pericytes, glioma cells; binds to } \\
\text { collagen VI and CD44. } \\
\text { LPs: bind to HA \& lecticans; stabilize binding of core protein to HA. } \\
\text { HSPGs: bind to basal lamina of blood vessels, ependymal, astroglial, } \\
\text { endothelial surfaces; storage site for cytokines and growth factors. }\end{array}$ \\
\hline Tenascin:C\& R, (glycoproteins) & + & +++ & $\begin{array}{l}\text { Tenascins: expressed in zones of proliferation, migration and } \\
\text { morphogenesis; Tenascin-C is over expressed in glioma. }\end{array}$ \\
\hline Galectins, (lectins) & + & +++ & $\begin{array}{l}\text { Galectins: (glia \& endothelial cells), glycan binding proteins; } \\
\text { neuronal and non-neuronal network development, angiogenesis. }\end{array}$ \\
\hline $\begin{array}{l}\text { Fibrous Proteins } \\
\begin{array}{c}\text { - } \\
\text { - follagens } \\
\text { - laminins } \\
\text { - } \text { vitronectin }\end{array}\end{array}$ & $\begin{array}{l}\text { In blood } \\
\text { vessels only }\end{array}$ & $\begin{array}{l}+ \\
+ \\
+ \\
+\end{array}$ & $\begin{array}{l}\text { Fibrous proteins: structural elements of connective tissue in blood } \\
\text { vessels' basement membrane in normal brain and glioma; in high } \\
\text { grade glioma also expressed by glioma cells. }\end{array}$ \\
\hline $\begin{array}{l}\text { Matrix metalloproteinases } \\
\text { (MMPs), proteases }\end{array}$ & + & +++ & $\begin{array}{l}\text { MMPs: tissue, ECM remodeling, angiogenesis; MMP-2,-9, }-13 \text { and } \\
\text { MT1-MMP play a role in glioma progression }\end{array}$ \\
\hline
\end{tabular}

Table 1. ECM molecules and their functional significance

\subsection{Proteases in glioma}

The local infiltration of neoplastic cells into healthy CNS parenchyma is the hallmark of gliomas. In this context it is relevant to note that the brain extracellular matrix differs in its composition from other such matrices and that glioma cells have the ability to exploit this environment for invasion. Glioma cells aggressively disseminate as single cells through this unique ECM of the central nervous system. They infiltrate along the periphery of blood vessels or along the longitudinal white matter tracts utilizing different proteolytic enzymes, to achieve their goal of both invasion and metastasis. Serine, cysteine and metalloproteinases are employed to breakdown connective tissue barriers, induce angiogenesis and penetrate normal brain tissue thereby achieving the invasive phenotype (reviewed by Rao 2003). The urokinase plasminogen activator (uPA)/plasmin system of the serine protease family have been shown to be up-regulated in gliomas (Lakka and Rao 2008) and high uPA levels are associated with poor prognosis. Cathepsin B is a lysosomal cysteine protease shown to be secreted at increased levels in gliomas, with expression being significantly higher in glioblastoma than in low-grade glioma and normal brain (Rao 2003, Lakka and Rao 2008). 
The third and the most widely studied protease system implicated in gliomas are the matrix metalloproteinases (MMPs). MMPs are a diverse family of endopeptidases that utilize zinc at their active site and encompass a broad spectrum of substrates. Common structural features of MMPs include a signal peptide, a catalytic domain which harbors the conserved zinc-binding site and a hemopexin-like domain. The proteolytic activity of MMPs affects diverse cellular functions such as cell proliferation, adhesion, migration, angiogenesis, bone development, wound healing and mammary involution, among others, by virtue of cleavage of ECM constituents, pro-growth factors, growth factor receptors and cell adhesion molecules. Within the tumor microenvironment, MMPs have been well documented to play a critical role in metastasis and angiogenesis (Kessenbrock et al. 2010).

The family of Metzincin proteinases to which the MMPs belong also includes ADAM (a disintegrin and metalloproteinase) and ADAMTS (a disintegrin and metalloproteinase with thrombospondin motifs). The ADAMs are mostly cell associated, and responsible for cleavage of other proteins like amyloid precursor protein and Notch and hence are also called "sheddases". On the other hand the ADAMTS are secreted (Murphy 2008). The role of ADAMs family members in nervous system development has been documented (Yang et al. 2006).Though these two subfamilies have not been extensively studied in glioma, there is some documentation of their role in these tumors. In this context, it has been shown that ADAM 8 and 19 are overexpressed in glioma correlating with invasion. ADAMTS 4 and 5 cleave brevican, a component of the ECM in the normal brain and have been shown to be upregulated in glioma cells (Rivera et al. 2010).

\subsection{MMPs and their inhibitors (TIMPs) in glioma}

MMPs span a wide range of subtypes within this family of endopeptidases that utilize zinc at their active site and interact with different targets. The proteolytic activity of MMPs affects diverse cellular functions as mentioned above, particularly impacting cell proliferation, adhesion, migration and angiogenesis. Thus they are important effectors of tissue remodeling, acting at various levels. The human MMP family comprises of over 23 members and cleaves every component of the ECM. They are classified as follows:

1. The archetypal MMPs: these include the collagenases i.e. MMP-1, MMP-8 and MMP-13; Stromelysins include MMP-3, MMP-10, MMP-11; Other archetypal MMPs e.g. the metalloelastase i.e MMP-12, also includes MMP-12, MMP-19, MMP-20 and MMP-27

2. Matrilysins include MMP-7 and MMP-26

3. Gelatinases include MMP-2 and MMP-9

4. Membran-type (MT)-MMPs include MMP-14, MMP-15, MMP-16, MMP-17, MMP-24 and MMP-25 A subgroup of glycosylphosphatidylinositol (GPI) MT-MMP includes MMP-17 and MMP-25.

5. Type II transmembrane MMPs include MMP-23A and MMP-23B-identical proteins encoded by distinct genes.

The MT-MMPs are covalently linked to the cell surface, however secreted ones can also attach to the cell membrane by either binding to integrins or to CD44. MMPs are produced in cells as zymogens where cysteine from the pro-domain is bound to zinc at the catalytic site and require proteolytic cleavage for activation. Activation of MMPs often requires cleavage by other MMPs, or serine proteases outside the cell. However some, including the membrane-type MMPs, are activated intracellularly (Egeblad and Werb 2002). Besides activation of pro-enzymes, MMP activity is also regulated by gene expression, compartmentalization and inhibition of active enzymes by their specific tissue inhibitors. 
Tissue inhibitors of metalloproteinases (TIMPs) are specific endogenous inhibitors of MMPs that have been correlated both positively and negatively in glioma invasion.

\subsubsection{MMPs in glioma}

MMP up-regulation has been implicated in several broad disease categories including inflammation, vascular pathologies, and cancer. Analysis of MMP expression in cancer patients show strong correlation between increased expression of many MMPs and tumor progression in a wide range of malignancies including gliomas. Within the tumor, MMPs are secreted by tumor cells, as well as by stromal cells of the tumor (Rojiani et al. 2010). It appears that tumor cells produce a potent factor called extracellular matrix metalloproteinase inducer (EMMPRIN) a cell surface glycoprotein of the immunoglobulin superfamily. EMMRPIN stimulates MMP expression in stromal cells and also in tumor cells (Jodele et al. 2006).

Several studies have documented overexpression of MMPs in gliomas compared to normal brain tissue. However the MMPs involved in gliomas have almost exclusively been the gelatinases MMP-2 and MMP-9 (reviewed by Rao 2003).

The glioma vasculature as well as infiltrating inflammatory cells, which form a portion of the glioma mass have been implicated in MMP expression (VanMeter et al. 2001). Strong gelatinase expression correlates with tumor grade (Forsyth et al. 1999, Wang et al. 2003). Intracranial implantation of glioblastoma cells in nude mice resulted in increased levels of MMP-9 during growth (Sawaya et al. 1998, Chintala et al. 1999). Raithatha et al. (Raithatha et al. 2000) carried out an RNA and protein localization study for gelatinases in a set of human gliomas with varied malignancy. They found that MMP-2 expression was most prominent in tumor cells whereas MMP-9 expression was seen in tumor cell but was more strongly expressed in the vasculature. Nakagawa et al. (Nakagawa et al. 1994) reported increased MMP-9 levels in blood vessels at proliferating margins. Recently Zhang et al. (Zhang et al. 2009) showed that knockdown of Akt2 resulted in decreased MMP-9 expression with concomitant decrease in glioma invasion in vitro and in vivo. It should be pointed out that EMMPRIN levels have been shown to increase in glioma and correlate with tumor grade (Sameshima et al. 2000). EMMPRIN has also been shown to increase hyaluronan and colocalizes with its receptor CD44 (Toole and Slomiany 2008). Given that Hyaluronan and CD44 are important players in the CNS and in gliomas (see section 3.4.1) EMMPRIN may play a significant role in glioma invasion.

In vitro studies also manifest a strong correlation between the expression of gelatinases and glioma cell invasion (reviewed by Bellail et al. 2004). Using matrigel assay, it was shown that the most invasive GBM cell line produced the highest level of gelatinases (Uhm et al. 1996, Abe et al. 1994). Besides the gelatinases, there are a number of studies documenting the role of MT1-MMP as well as reports of other MMPs involved in gliomas. Lampert et al. (Lampert et al. 1998) found increased levels of gelatinases as well as MT1-MMP and MT2-MMP in brain tumors. Yamamoto et al. (Yamamoto et al. 1996) found that increased MT1-MMP expression is associated with the expression of activated form of MMP-2 which in turn correlated with malignant glioma progression in vivo. Overexpression of MT1-MMP in glioma cell lines leads to activation of pro-MMP-2 (Nakada et al. 2001, Deryugina et al. 1997). Additionally, other studies show that MT1-MMP is increased in glioma-associated microglia and that glioma-released factors trigger this expression by microglia. The MT1MMP then activates glioma-derived proMMP-2 and promotes glioma expansion (Markovic et al. 2009). The known classical function of MT1-MMP is activation of proMMP-2 in 
conjunction with TIMP-2. A complex of MT1-MMP and TIMP-2 interacts with proMMP-2 thus resulting in cleavage of the pro-domain from MMP-2 (Murphy et al. 1999). Hence, it is not surprising that many studies on glioma define activation of proMMP-2.

The gelatinases MMP-2 and MMP-9 as well as the membrane-type protease MT1-MMP have been well documented to play pivotal roles in invasion and angiogenesis (Handsley and Edwards 2005). Vascular basement membrane components are well recognized substrates of MMP-2 and MMP-9. MMP-9 is a known component of the angiogenic switch regulating the bioavailability of VEGF (Bergers et al. 2000). MMP-2 expression has been correlated with the degree of vascularization of tumor nodules (Fang et al. 2000). MT1-MMP deficient mice have provided convincing evidence for its role in angiogenesis (reviewed by Handsley and Edwards 2005). These same MMPs are found at the invasive front of the tumor. Invadopodia are actin-rich protrusions of tumor cells with proteolytic activity. The gelatinases and the MT1-MMP localize to or become activated at the invadopodia (Stylli et al. 2008).

Within the realm of glioma angiogenesis, the gelatinases remain crucial. MMP-2 and MMP-9 showed positive correlation with glioma invasion and angiogenesis (Wang et al. 2003). In a mouse model, glioma growth required host MMP-2 to support angiogenesis (Takahashi et al. 2002). Small interferring RNA (siRNA)-mediated targeting of MMP-9 inhibits glioma angiogenesis in in vitro and in vivo models (Lakka et al. 2005). Hypoxia-inducible factor-1 a (HIF1a) was shown to induce recruitment of CD45+ cells amongst other cellular components, in a murine glioblastoma model. MMP-9 activity of these bone marrow derived CD45+ cells was essential and sufficient to initiate angiogenesis by increasing VEGF bioavailability (Du et al. 2008).

With regard to other MMPs, Lettau et al. (Lettau et al. 2010) have found that MMP-19 is strongly expressed in astroglial tumors and is also responsible for the invasion of glioma cells in vitro. In a study using the glioma cell line U251, Deng et al. (Deng et al. 2010) found that MMP-26 promoted cell invasion in vitro and in vivo. Stojic et al. (Stojic et al. 2008) have shown enhanced expression of MMP-1, MMP-11 and MMP-19 in glioblastoma multiforme in comparison to low grade astrocytomas and normal brain. Tenascin-C is an ECM protein of the brain parenchyma and its synthesis is known to be up-regulated in glioma. MMP-12 was implicated in the invasion of glioma cell lines using tenascin- $\mathrm{C}$ in a three-dimensional matrix model (Sarkar et al. 2006).

Hence, it appears that MMPs play a pivotal role in glioma aggressiveness which would appear to make them potential targets for therapy. However, it should be pointed out that MMPs, by virtue of their degradation capacity also generate endogenous angiogenesis inhibitors. Proteolytic cleavage of plasminogen by several MMPs generates angiostatin and endostatin is generated from the C-terminal fragment of collagen type XVIII. MMP-9 is involved in the release of Tumstatin, another inhibitor of angiogenesis. MMPs as potential targets are further discussed below.

\subsubsection{Tissue Inhibitors of Matrix Metalloproteinases (TIMPS) in glioma}

As mentioned above, MMP regulation occurs at four different levels i.e. transcription, zymogen activation, compartmentalization and natural endogenous inhibition. Inhibition by $\mathrm{a}_{2}$-macroglobulin and tissue inhibitors of metalloproteinases (TIMPs) occurs in the liquid phase and in tissues, respectively (Nagase et al. 1999, Brew et al. 2000). Although TIMPs have been known for their primary function of inhibiting MMPs, it has now been widely recognized that TIMPs exhibit additional biological activities independent of their MMP inhibitory function. There are four TIMP members: TIMP-1, TIMP-2, TIMP-3 and TIMP-4, all of which 
inhibit MMP activity. TIMP-1, -2 and -4 are secreted, whereas TIMP-3 is associated with the extracellular matrix. They are differentially regulated i.e. TIMP-1 expression is inducible, whereas TIMP-2 expression is constitutive (Gomez et al. 1997, Nagase et al. 1999).

The MMP-independent activity of TIMPs includes promotion of cell growth as exhibited by TIMP-1 and TIMP-2, apoptosis, angiogenesis as well as a role in cell signaling. These roles of TIMPs surfaced when overexpression of these molecules gave conflicting results. There are several earlier studies showing an inhibitory role of TIMPs in tumor growth and metastasis; however, a number of studies have also demonstrated a tumor-promoting function and serum levels of TIMP correlated with poor prognosis as well (reviewed by Rojiani et al. 2010).

This paradoxical tumor promoting and tumor inhibiting role of TIMPs extends to gliomas as well. In the normal murine brain TIMP-2, -3 and -4 are strongly expressed whereas there is very little TIMP-1 expression (reviewed by Crocker et al. 2004) . Studies demonstrating the classical role of TIMP show, for example, that adding TIMP-2 to cultured glioblastoma cells reduces their invasion (Rao et al. 1994). Likewise, use of recombinant TIMP-1 on glioma cells showed reduced glioma invasion (VanMeter et al. 2001). Also, TIMP-1 was shown to cause significant reduction in brain metastasis of implanted fibrosarcoma cells (Kruger et al. 1998) and a decrease in TIMP-2 levels in glioblastomas has been noted as well (Lampert et al. 1998). TIMP-3 overexpression suppresses glioma cell infiltration (Baker et al. 1999). Interestingly, TIMP-3 gene is one of the most highly methylated genes found in brain tumors (Esteller et al. 2001) and has been referred to as a tumor suppressor.

Nakada et al. (Nakada et al. 2001) found that TIMP-1 but not TIMP-2 levels were significantly higher in glioblastoma multiforme compared to other glioma grades when using sandwich enzyme immunoassays. The same study developed stable transfectants of MT1-MMP and found that invasion and gelatinase activity of these transfectants could be totally inhibited by recombinant TIMP-2 but not recombinant TIMP-1. Lampert et al. (Lampert et al. 1998) have demonstrated a significant increase in TIMP-1 levels in glioblastomas compared to low grade tumors. Pagenstecher et al. (Pagenstecher et al. 2001) investigated the expression profiles of 9 MMPs and all TIMPs in different gliomas and found that TIMP-1 expression was the highest in GBMs and grade I gliomas with expression being confined to walls of neovessels. Groft et al. (Groft et al. 2001) carried out an extensive study looking at the expression and localization of all four TIMPs in normal human brains and gliomas. A detailed analysis of the expression of mRNA and protein levels showed that TIMP-2 and TIMP-3 expression pattern did not alter with tumor grade. However TIMP-1 levels correlated positively with glioma malignancy, whereas TIMP-4 correlated negatively. TIMP-1 transcript expression was localized to tumor cell and the surrounding tumor vasculature while TIMP-4 transcripts were found mainly in tumor cells with minor expression seen in vessels. These authors also showed that in an in vitro assay, recombinant TIMP-4 reduced invasion of U251 glioma cells through Matrigel. Thus, although TIMPs have clearly been shown to play a significant role in the invasive and growth aspects of glioma, their precise roles remain elusive. However, TIMPs deserve further consideration in the search for targeted therapies.

\section{Therapeutic targeting of ECM molecules in glioma}

\subsection{Targeting metalloproteinases}

MMPs play a crucial role in tumor growth, metastasis and angiogenesis and therefore have been the targets of antitumor therapy. Due to highly pleiotropic activities of MMPs the 
outcomes of the clinical studies targeting these molecules have been disappointing, resulting often in increased tumor growth (reviewed by Rojiani et al. 2011). The initial use of broad spectrum MMP inhibitors interfering with the function of many of these enzymes in clinical trials had unforeseen consequences and resulted in early termination of these studies (reviewed by Coussens et al. 2002). These disappointing results led to the realization that the experimental data had to be reevaluated. For example, in animal studies the inhibitors were administered in early or intermediate stages of cancer whereas in humans they were administered in advanced stages. Besides, it has now been well documented that a number of MMPs play a protective role and their elimination can have adverse consequences (Martin and Matrisian 2007).

However, given their significant contribution to tumor progression, MMPs still remain strong potential target candidates for therapeutic interventions. Therefore, it is not surprising that there are a number of MMP inhibitors (MMPI) in clinical trials (reviewed by Roy et al. 2009). Their effectiveness has yet to be proven. Also, the timing of delivery has been reconsidered since drugs given at earlier stages of cancer appear to be more effective than when given in advanced stages (Roy et al. 2009).

Despite the adaptation of clinical trials and because of the pleiotropic activities of MMPs, a prediction of outcome is still difficult. Therefore, attention is now also given to other ECM molecules in the glioma microenvironment. New classes of targets need to be identified, eg. ECM molecules found within the cancer stem cell niche. Examples of other ECM targets are discussed below (sections 5.2, 6.1 and 6.2).

\subsection{Targeting HA and CD44 adhesion molecule}

We showed previously that blocking CD44 and interfering with HA-CD44 ligand-receptor interaction resulted in inhibition of glioma cell invasion, decreased HA production and led to glioma cell apoptosis (Wiranowska et al. 1998, Wiranowska et al. 2010). In addition, recent data by $\mathrm{Xu}$ et al. (Xu et al. 2010) showed that CD44 attenuates activation of the Hippo signaling pathway and that knockdown of CD44 expression resulted in the inhibition of glioblastoma. It was suggested that CD44 is a prime therapeutic target for treatment of glioblastoma ( $\mathrm{Xu}$ et al. 2010). Therefore, further studies of this promising biological target molecule in glioma are warranted. The soluble recombinant CD44-HA-binding domain (CD44-HABD) inhibited proliferation of endothelial cells in vitro, blocked angiogenesis in vivo and inhibited growth of various tumors (Pall et al. 2004) providing hope for a new therapeutic approach to glioma. In addition, HA was recently used in vivo as a delivery carrier for chemotherapeutic paclitaxel (HA-paclitaxel) targeting CD44 positive ovarian carcinoma (Auzenne et al. 2007). Also, recently cisplatin carrying HA nanoparticles were evaluated as potential treatment for cancer (Jeong et al. 2008).

\section{Future therapies of glioma}

\subsection{ECM therapeutic targets: Hopes and disappointments}

Current therapies like surgery, radiotherapy and chemotherapy are aimed at debulking of the brain tumor mass as well as targeting and eradicating proliferating tumor cells. However, these therapies do not address the quiescent population of the cancer stem cells. These cells, which are nourished and protected from therapeutic interventions by the microenvironment of the CSCs vascular niche can repopulate and initiate new tumor foci in the brain (Denysenko et al. 2010) 
The modulation of the ECM microenvironment of the stem cell niche may be a promising approach especially in light of the finding that many of the genes and their products prognostic for the faith of proneural GBM were identified in the stroma of the brain tumor but not in the brain tumor cells themselves (as mentioned in Section 1: Holland 2011). Therapies targeting solely the brain tumors and their CSCs population may not be successful due to the high complexity and heterogeneity of brain tumors as demonstrated by the existence of various subtypes of GBMs. In addition, the genetic instability in expressing markers for undifferentiated cells within these tumors makes it difficult to assign the correct differentiation status of the tumor cells (Denysenko et al. 2010). Therefore, other therapeutic options should be pursued including therapies targeting the ECM of the CSCs vascular niches which would disrupt the microenvironment protective and supportive of the CSCs' self-renewal.

One of the stimulatory pro-angiogenic molecules released within the CSCs niche which enhances the survival of neural stem cells is VEGF (section 3.2). It has been shown that targeting VEGF and disruption of the niches by anti-VEGF treatment in vivo resulted in CSCs depletion and tumor growth inhibition (Calabrese et al. 2007). Some other studies however, showed that blocking VEGF in vivo resulted in growth of satellite tumors (Rubenstein et al. 2000). The early data obtained from clinical trials of GBM patients using VEGF-specific inhibitors such as bevacizumab combined with chemotherapeutic drug CPT11, showed promising results (Calabrese et al. 2007). However, recent finding by RicciVitiani et al. (Ricci-Vitiani et al. 2010) and Wang et al. (Wang et al. 2010) showed that newly formed blood vessels originating from the GBM stem cells that differentiated into endothelial cells were not responsive to anti-VEGF therapy (section 3.2). Most recently, it has been shown (di Tomaso et al. 2011) that patients treated with anti-VEGF therapy still contained Nestin + cells, a characteristic marker of the CSCs, despite a decreased vascularization of the brain tumors. The phase II results from anti-VEGF therapy in combination with chemotherapeutic CPT-11 failed to show prolonged survival of the GBM patients (Lai et al. 2011). Similar results were obtained from phase III clinical studies with recurrent GBM patients treated with cediranib, an inhibitor of VEGF alone or in combination with chemotherapeutic lomustine (Batchelor, 2010). In addition, it was shown recently by Takano et al. (Takano et al. 2010) that failure of bevacizumab treatment was associated with the high incidence of infiltrative tumors and MMP activity in the samples of urine. Therefore, based on the current state of knowledge, other approaches targeting ECM molecules of the vascular niche of CSCs need to be developed.

\subsection{Glioma possible new prognostic factors and new targets 6.2.1 ECM prognostic factors}

There is evidence that some ECM molecules could serve as prognostic markers of antiangiogenic therapy of glioma indicative of the fate of the therapy. For example, Takano et al. (Takano et al. 2010) found that failure of bevacizumab (anti-VEGF antibody) treatment was associated with the high incidence of infiltrative tumors and levels of MMP activity in urine. Therefore, early detection and measurement of urine MMPs activity in samples from patients could be indicative of progressive disease. The detection of this biomarker could allow for earlier therapeutic intervention or alteration of a given anti-glioma therapy. Another ECM prognostic factor of potential therapeutic value could be presence of soluble collagen IV in the blood. It was shown by Sorensen et al. (Sorensen et al. 2009) that in patients treated with anti-angiogenic therapy using cediranib (pan-VEGF receptor tyrosine 
kinase inhibitor) increased levels of collagen IV were found. This increase in circulating collagen IV was explained as the result of "blood vessels normalization" involving thinning of the abnormally thick tumor associated basement membrane of blood vessels. Increased levels of circulating collagen IV were associated with progression-free and overall patient survival.

\subsubsection{New ECM targets}

Recent data by Inoue et al. (Inoue et al. 2010) showed that cancer stem-like cells of GBM express MMP-13 responsible for invasion and migration of these cells suggesting that, MMP-13 might be a potential new therapeutic target for glioblastomas. Blocking VEGF or silencing VEGF receptor 2 inhibits the maturation of tumor endothelial progenitors into endothelium but does not stop the differentiation of CSCs (CD133+ cells) into endothelial cells. However, silencing of Notch (neural precursor receptor as mentioned in section 2.2) blocks the transition of CSCs (CD133+ cells) into endothelial progenitors (Wang et al. 2010). Therefore, Notch may be another potential new target in the stem cell niche. Fujita et al. (Fujita et al. 2011) showed that non-steroidal anti-inflammatory drugs (NSAID) such as Cox2 inhibitors suppressed gliomagenesis via inhibition of prostaglandin E2 mediated accumulation of myeloid derived suppressor cells. In addition, as mentioned earlier (section 3.1) the Cox-2 inhibitor, celecoxib, inhibited in vitro microvascular channel formation associated with VEGF down regulation (Basu et al. 2005). The effect was more pronounced and prostaglandin E2-independent in a highly invasive breast cancer cell line when compared to a less invasive cell line. Based on these findings, it could be hypothesized that the NSAID class may have potential application in highly invasive glioma by targeting of the inflammatory molecules and immune cells as well as VM channel formation in the ECM.

\section{Summary and conclusions}

Despite years of research, glioma therapy remains a challenge due to very limited therapeutic options and short survival of glioma patients (as described in section 1). Until recently the focus of research evaluating possible target molecules for treatment was mainly on the cancer cell itself and its genetic characterization. Therefore, routine anti-glioma therapies such as chemotherapy or radiation are solely focused on targeting proliferating glioma cells by interfering with their cell cycle and resulting in glioma cell death. Very little attention was given to evaluation and validation of therapeutic targets in the extracellular matrix in glioma, its vasculature and brain stroma outside the tumor. Recent clinical trials targeting glioma vasculature with anti-angiogenic molecules initially provided encouraging results but later failed to be effective in slowing glioma progression. On the contrary, some of the anti-angiogenic treatments despite achieving blood vessel "normalization" within the tumor later resulted in the development of new glioma foci in the brain parenchyma away from the main lesion. It became known recently that a population of glioma CSCs present within the tumors was capable of escaping this anti-angiogenic therapy giving rise to tumor endothelium which had no markers for anti-angiogenic therapy.

Another attempt to stop glioma cell invasion into the normal brain parenchyma involved targeting various MMPs responsible for remodeling ECM during glioma progression. Although there were high expectations, the results of these studies were disappointing again. It was found that many of the targeted MMPs had anti-tumor as well as tumorigenic activities and blocking or eliminating their activity lead to glioma regrowth. Clearly, the 
ECM and the surrounding stroma play an essential role in glioma progression but more studies need to be done in order to find proper targets within the ECM to slow or inhibit glioma growth. This is supported by most recent finding by Holland (Holland 2011) that genes expressed in the microenvironment of the stroma rather than in the glioma itself may be predictive of glioma patient survival. This chapter provides a review of recent information relating to ECM targets for anti-glioma therapy. Consideration was given to various ECM molecules within the normal brain, in glioma and in the vascular niche harboring glioma stem cells. Consideration was also given to ECM rigidity and its effect on glioma progression. In addition to discussing some pertinent ECM molecules in glioma progression, also new emerging ECM targets and new prognostic markers candidates were discussed. All in all, ECM molecules are of great importance in the development of new therapeutic strategies and the information compiled in this chapter summarizing their role should be suitable to give guidance for the search and the development of new ECM antiglioma targets.

\section{References}

Abaskharoun, M., Bellemare, M., Lau, E. and Margolis, R. U. (2010). "Expression of hyaluronan and the hyaluronan-binding proteoglycans neurocan, aggrecan, and versican by neural stem cells and neural cells derived from embryonic stem cells." Brain Res 1327: 6-15.

Abe, T., Mori, T., Kohno, K., Seiki, M., Hayakawa, T., Welgus, H. G., Hori, S. and Kuwano, M. (1994). "Expression of $72 \mathrm{kDa}$ type IV collagenase and invasion activity of human glioma cells." Clin Exp Metastasis 12(4): 296-304.

Annabi, B., Bouzeghrane, M., Moumdjian, R., Moghrabi, A. and Beliveau, R. (2005). "Probing the infiltrating character of brain tumors: inhibition of RhoA/ROK-mediated CD44 cell surface shedding from glioma cells by the green tea catechin EGCg." J Neurochem 94(4): 906-16.

Auzenne, E., Ghosh, S. C., Khodadadian, M., Rivera, B., Farquhar, D., Price, R. E., Ravoori, M., Kundra, V., Freedman, R. S. and Klostergaard, J. (2007). "Hyaluronic acidpaclitaxel: antitumor efficacy against CD44(+) human ovarian carcinoma xenografts." Neoplasia 9(6): 479-86.

Baker, A. H., George, S. J., Zaltsman, A. B., Murphy, G. and Newby, A. C. (1999). "Inhibition of invasion and induction of apoptotic cell death of cancer cell lines by overexpression of TIMP-3." Br J Cancer 79(9-10): 1347-55.

Batchelor, T.(2010) 15th Annual Scientific Meeting of Society for Neuro-Oncology , Abstract OT-25, November, 19, 2010

Bao, S., Wu, Q., Sathornsumetee, S., Hao, Y., Li, Z., Hjelmeland, A. B., Shi, Q., McLendon, R. E., Bigner, D. D. and Rich, J. N. (2006). "Stem cell-like glioma cells promote tumor angiogenesis through vascular endothelial growth factor." Cancer Res 66(16): 78438.

Basu, G. D., Pathangey, L. B., Tinder, T. L., Gendler, S. J. and Mukherjee, P. (2005). "Mechanisms underlying the growth inhibitory effects of the cyclo-oxygenase-2 inhibitor celecoxib in human breast cancer cells." Breast Cancer Res 7(4): R422-35.

Bellail, A. C., Hunter, S. B., Brat, D. J., Tan, C. and Van Meir, E. G. (2004). "Microregional extracellular matrix heterogeneity in brain modulates glioma cell invasion." Int J Biochem Cell Biol 36(6): 1046-69. 
Ben-Hur, T., Ben-Yosef, Y., Mizrachi-Kol, R., Ben-Menachem, O. and Miller, A. (2006). "Cytokine-mediated modulation of MMPs and TIMPs in multipotential neural precursor cells." J Neuroimmunol 175(1-2): 12-8.

Bergers, G., Brekken, R., McMahon, G., Vu, T. H., Itoh, T., Tamaki, K., Tanzawa, K., Thorpe, P., Itohara, S., Werb, Z. and Hanahan, D. (2000). "Matrix metalloproteinase-9 triggers the angiogenic switch during carcinogenesis." Nat Cell Biol 2(10): 737-44.

Bolteus, A. J., Berens, M. E. and Pilkington, G. J. (2001). "Migration and invasion in brain neoplasms." Curr Neurol Neurosci Rep 1(3): 225-32.

Brew, K., Dinakarpandian, D. and Nagase, H. (2000). "Tissue inhibitors of metalloproteinases: evolution, structure and function." Biochim Biophys Acta 1477(1-2): 267-83.

Brightman, M. W. (2002). "The brain's interstitial clefts and their glial walls." J Neurocytol 31(8-9): 595-603.

Brightman, M. W. and Kaya, M. (2000). "Permeable endothelium and the interstitial space of brain." Cell Mol Neurobiol 20(2): 111-30.

Cancer Genome Atlas Res. Network, 2008 Comprehensive genomic charachterization defines human glioblastoma genes and core pathways, Nature, vol. 455, No 7216, pp.1061-1068

Calabrese, C., Poppleton, H., Kocak, M., Hogg, T. L., Fuller, C., Hamner, B., Oh, E. Y., Gaber, M. W., Finklestein, D., Allen, M., Frank, A., Bayazitov, I. T., Zakharenko, S. S., Gajjar, A., Davidoff, A. and Gilbertson, R. J. (2007). "A perivascular niche for brain tumor stem cells." Cancer Cell 11(1): 69-82.

Chintala, S. K., Kyritsis, A. P., Mohan, P. M., Mohanam, S., Sawaya, R., Gokslan, Z., Yung, W. K., Steck, P., Uhm, J. H., Aggarwal, B. B. and Rao, J. S. (1999). "Altered actin cytoskeleton and inhibition of matrix metalloproteinase expression by vanadate and phenylarsine oxide, inhibitors of phosphotyrosine phosphatases: modulation of migration and invasion of human malignant glioma cells." Mol Carcinog 26(4): 274-85.

Coussens, L. M., Fingleton, B. and Matrisian, L. M. (2002). "Matrix metalloproteinase inhibitors and cancer: trials and tribulations." Science 295(5564): 2387-92.

Crocker, S. J., Pagenstecher, A. and Campbell, I. L. (2004). "The TIMPs tango with MMPs and more in the central nervous system." J Neurosci Res 75(1): 1-11.

Deed, R., Rooney, P., Kumar, P., Norton, J. D., Smith, J., Freemont, A. J. and Kumar, S. (1997). "Early-response gene signalling is induced by angiogenic oligosaccharides of hyaluronan in endothelial cells. Inhibition by non-angiogenic, high-molecularweight hyaluronan." Int J Cancer 71(2): 251-6.

Delpech, B., Maingonnat, C., Girard, N., Chauzy, C., Maunoury, R., Olivier, A., Tayot, J. and Creissard, P. (1993). "Hyaluronan and hyaluronectin in the extracellular matrix of human brain tumour stroma." Eur J Cancer 29A(7): 1012-7.

Deng, Y., Li, W., Li, Y., Yang, H., Xu, H., Liang, S. and Zhang, L. (2010). "Expression of Matrix Metalloproteinase-26 promotes human glioma U251 cell invasion in vitro and in vivo." Oncol Rep 23(1): 69-78.

Denysenko, T., Gennero, L., Roos, M. A., Melcarne, A., Juenemann, C., Faccani, G., Morra, I., Cavallo, G., Reguzzi, S., Pescarmona, G. and Ponzetto, A. (2010). "Glioblastoma cancer stem cells: heterogeneity, microenvironment and related therapeutic strategies." Cell Biochem Funct 28(5): 343-51. 
Deryugina, E. I., Bourdon, M. A., Luo, G. X., Reisfeld, R. A. and Strongin, A. (1997). "Matrix metalloproteinase-2 activation modulates glioma cell migration." J Cell Sci 110 ( Pt 19): 2473-82.

di Tomaso, E., Snuderl, M., Kamoun, W. S., Duda, D. G., Auluck, P. K., Fazlollahi, L., Andronesi, O. C., Frosch, M. P., Wen, P. Y., Plotkin, S. R., Hedley-Whyte, E. T., Sorensen, A. G., Batchelor, T. T. and Jain, R. K. (2011). "Glioblastoma recurrence after cediranib therapy in patients: lack of "rebound" revascularization as mode of escape." Cancer Res 71(1): 19-28.

Doetsch, F. (2003). "A niche for adult neural stem cells." Curr Opin Genet Dev 13(5): 543-50.

Du, R., Lu, K. V., Petritsch, C., Liu, P., Ganss, R., Passegue, E., Song, H., Vandenberg, S., Johnson, R. S., Werb, Z. and Bergers, G. (2008). "HIF1alpha induces the recruitment of bone marrow-derived vascular modulatory cells to regulate tumor angiogenesis and invasion." Cancer Cell 13(3): 206-20.

Egeblad, M. and Werb, Z. (2002). "New functions for the matrix metalloproteinases in cancer progression." Nat Rev Cancer 2(3): 161-74.

El Hallani, S., Boisselier, B., Peglion, F., Rousseau, A., Colin, C., Idbaih, A., Marie, Y., Mokhtari, K., Thomas, J. L., Eichmann, A., Delattre, J. Y., Maniotis, A. J. and Sanson, M. (2010). "A new alternative mechanism in glioblastoma vascularization: tubular vasculogenic mimicry." Brain 133(Pt 4): 973-82.

Elkin , B.S., BS., Azeloglu, EU., Costa KD., Morrison B3rd (2007). “Mechanical heterogeneity of the rat hippocampus measured by atomic force microscope indentation". J.Neurotrama, 24, 812-822.

Esteller, M., Corn, P. G., Baylin, S. B. and Herman, J. G. (2001). "A gene hypermethylation profile of human cancer." Cancer Res 61(8): 3225-9.

Fang, J., Shing, Y., Wiederschain, D., Yan, L., Butterfield, C., Jackson, G., Harper, J., Tamvakopoulos, G. and Moses, M. A. (2000). "Matrix metalloproteinase-2 is required for the switch to the angiogenic phenotype in a tumor model." Proc Natl Acad Sci U S A 97(8): 3884-9.

Folkman, J. (1998). "Antiangiogenic gene therapy." Proc Natl Acad Sci U S A 95(16): 9064-6.

Forsyth, P. A., Wong, H., Laing, T. D., Rewcastle, N. B., Morris, D. G., Muzik, H., Leco, K. J., Johnston, R. N., Brasher, P. M., Sutherland, G. and Edwards, D. R. (1999). "Gelatinase-A (MMP-2), gelatinase-B (MMP-9) and membrane type matrix metalloproteinase-1 (MT1-MMP) are involved in different aspects of the pathophysiology of malignant gliomas." Br J Cancer 79(11-12): 1828-35.

Fujita, M., Kohanbash, G., Fellows-Mayle, W., Hamilton, R. L., Komohara, Y., Decker, S. A., Ohlfest, J. R. and Okada, H. (2011). "COX-2 Blockade Suppresses Gliomagenesis by Inhibiting Myeloid-Derived Suppressor Cells." Cancer Res 71(7): 2664-74.

Galli, R., Binda, E., Orfanelli, U., Cipelletti, B., Gritti, A., De Vitis, S., Fiocco, R., Foroni, C., Dimeco, F. and Vescovi, A. (2004). "Isolation and characterization of tumorigenic, stem-like neural precursors from human glioblastoma." Cancer Res 64(19): 7011-21.

Gomez, D. E., Alonso, D. F., Yoshiji, H. and Thorgeirsson, U. P. (1997). "Tissue inhibitors of metalloproteinases: structure, regulation and biological functions." Eur J Cell Biol 74(2): 111-22.

Groft, L. L., Muzik, H., Rewcastle, N. B., Johnston, R. N., Knauper, V., Lafleur, M. A., Forsyth, P. A. and Edwards, D. R. (2001). "Differential expression and localization of TIMP-1 and TIMP-4 in human gliomas." Br J Cancer 85(1): 55-63. 
Ha, H. Y., Moon, H. B., Nam, M. S., Lee, J. W., Ryoo, Z. Y., Lee, T. H., Lee, K. K., So, B. J., Sato, H., Seiki, M. and Yu, D. Y. (2001). "Overexpression of membrane-type matrix metalloproteinase-1 gene induces mammary gland abnormalities and adenocarcinoma in transgenic mice." Cancer Res 61(3): 984-90.

Handsley, M. M. and Edwards, D. R. (2005). "Metalloproteinases and their inhibitors in tumor angiogenesis." Int J Cancer 115(6): 849-60.

Hibino, S., Shibuya, M., Engbring, J. A., Mochizuki, M., Nomizu, M. and Kleinman, H. K. (2004). "Identification of an active site on the laminin alpha5 chain globular domain that binds to CD44 and inhibits malignancy." Cancer Res 64(14): 4810-6.

Holland, E C. (2011). "PDGF/Proneural GBMs: Microenvironment and Therapeutic response". Program of 102 Annual Am. Assoc for Cancer Res, April 2-6, 2011, p.190.

Inoue, A., Takahashi, H., Harada, H., Kohno, S., Ohue, S., Kobayashi, K., Yano, H., Tanaka, J. and Ohnishi, T. (2010). "Cancer stem-like cells of glioblastoma characteristically express MMP-13 and display highly invasive activity." Int J Oncol 37(5): 1121-31.

Jeong, Y. I., Kim, S. T., Jin, S. G., Ryu, H. H., Jin, Y. H., Jung, T. Y., Kim, I. Y. and Jung, S. (2008). "Cisplatin-incorporated hyaluronic acid nanoparticles based on ion-complex formation." J Pharm Sci 97(3): 1268-76.

Jodele, S., Blavier, L., Yoon, J. M. and DeClerck, Y. A. (2006). "Modifying the soil to affect the seed: role of stromal-derived matrix metalloproteinases in cancer progression." Cancer Metastasis Rev 25(1): 35-43.

Kearns, S. M., Laywell, E. D., Kukekov, V. K. and Steindler, D. A. (2003). "Extracellular matrix effects on neurosphere cell motility." Exp Neurol 182(1): 240-4.

Kessenbrock, K., Plaks, V. and Werb, Z. (2010). "Matrix metalloproteinases: regulators of the tumor microenvironment." Cell 141(1): 52-67.

Knott, J. C., Mahesparan, R., Garcia-Cabrera, I., Bolge Tysnes, B., Edvardsen, K., Ness, G. O., Mork, S., Lund-Johansen, M. and Bjerkvig, R. (1998). "Stimulation of extracellular matrix components in the normal brain by invading glioma cells." Int J Cancer 75(6): 864-72.

Knudson, C. B. and Knudson, W. (1993). "Hyaluronan-binding proteins in development, tissue homeostasis, and disease." FASEB J 7(13): 1233-41.

Kruger, A., Sanchez-Sweatman, O. H., Martin, D. C., Fata, J. E., Ho, A. T., Orr, F. W., Ruther, U. and Khokha, R. (1998). "Host TIMP-1 overexpression confers resistance to experimental brain metastasis of a fibrosarcoma cell line." Oncogene 16(18): 241923.

Kumar, S. (2009). "Cell-matrix mechanobiology: applications to brain tumors and design of tissue engineering scaffolds." Conf Proc IEEE Eng Med Biol Soc 2009: 3350-2.

Lai, A., Tran, A., Nghiemphu, P. L., Pope, W. B., Solis, O. E., Selch, M., Filka, E., Yong, W. H., Mischel, P. S., Liau, L. M., Phuphanich, S., Black, K., Peak, S., Green, R. M., Spier, C. E., Kolevska, T., Polikoff, J., Fehrenbacher, L., Elashoff, R. and Cloughesy, T. (2011). "Phase II study of bevacizumab plus temozolomide during and after radiation therapy for patients with newly diagnosed glioblastoma multiforme." J Clin Oncol 29(2): 142-8.

Lakka, S. S., Gondi, C. S. and Rao, J. S. (2005). "Proteases and glioma angiogenesis." Brain Pathol 15(4): 327-41.

Lakka, S. S. and Rao, J. S. (2008). "Antiangiogenic therapy in brain tumors." Expert Rev Neurother 8(10): 1457-73. 
Lampert, K., Machein, U., Machein, M. R., Conca, W., Peter, H. H. and Volk, B. (1998). "Expression of matrix metalloproteinases and their tissue inhibitors in human brain tumors." Am J Pathol 153(2): 429-37.

Lefranc, F., Brotchi, J. and Kiss, R. (2005). "Possible future issues in the treatment of glioblastomas: special emphasis on cell migration and the resistance of migrating glioblastoma cells to apoptosis." J Clin Oncol 23(10): 2411-22.

Lettau, I., Hattermann, K., Held-Feindt, J., Brauer, R., Sedlacek, R. and Mentlein, R. (2010). "Matrix metalloproteinase-19 is highly expressed in astroglial tumors and promotes invasion of glioma cells." J Neuropathol Exp Neurol 69(3): 215-23.

Lin, X. H., Dahlin-Huppe, K. and Stallcup, W. B. (1996). "Interaction of the NG2 proteoglycan with the actin cytoskeleton." J Cell Biochem 63(4): 463-77.

Ljubimova, J. Y., Fugita, M., Khazenzon, N. M., Das, A., Pikul, B. B., Newman, D., Sekiguchi, K., Sorokin, L. M., Sasaki, T. and Black, K. L. (2004). "Association between laminin-8 and glial tumor grade, recurrence, and patient survival." Cancer 101(3): 604-12.

Lo, C. M., Wang, H. B., Dembo, M. and Wang, Y. L. (2000). "Cell movement is guided by the rigidity of the substrate." Biophys J 79(1): 144-52.

Louis, D. N., Ohgaki, H., Wiestler, O. D., Cavenee, W. K., Burger, P. C., Jouvet, A., Scheithauer, B. W. and Kleihues, P. (2007). "The 2007 WHO classification of tumours of the central nervous system." Acta Neuropathol 114(2): 97-109.

Luke, H. J. and Prehm, P. (1999). "Synthesis and shedding of hyaluronan from plasma membranes of human fibroblasts and metastatic and non-metastatic melanoma cells." Biochem J 343 Pt 1: 71-5.

Mahesparan, R., Read, T. A., Lund-Johansen, M., Skaftnesmo, K. O., Bjerkvig, R. and Engebraaten, O. (2003). "Expression of extracellular matrix components in a highly infiltrative in vivo glioma model." Acta Neuropathol 105(1): 49-57.

Maniotis, A. J., Folberg, R., Hess, A., Seftor, E. A., Gardner, L. M., Pe'er, J., Trent, J. M., Meltzer, P. S. and Hendrix, M. J. (1999). "Vascular channel formation by human melanoma cells in vivo and in vitro: vasculogenic mimicry." Am J Pathol 155(3): 739-52.

Markovic, D. S., Vinnakota, K., Chirasani, S., Synowitz, M., Raguet, H., Stock, K., Sliwa, M., Lehmann, S., Kalin, R., van Rooijen, N., Holmbeck, K., Heppner, F. L., Kiwit, J., Matyash, V., Lehnardt, S., Kaminska, B., Glass, R. and Kettenmann, H. (2009). "Gliomas induce and exploit microglial MT1-MMP expression for tumor expansion." Proc Natl Acad Sci U S A 106(30): 12530-5.

Martin, M. D. and Matrisian, L. M. (2007). "The other side of MMPs: protective roles in tumor progression." Cancer Metastasis Rev 26(3-4): 717-24.

Mercier, F., Kitasako, J. T. and Hatton, G. I. (2003). "Fractones and other basal laminae in the hypothalamus." J Comp Neurol 455(3): 324-40.

Murphy, G. (2008). "The ADAMs: signalling scissors in the tumour microenvironment." Nat Rev Cancer 8(12): 929-41.

Murphy, G., Stanton, H., Cowell, S., Butler, G., Knauper, V., Atkinson, S. and Gavrilovic, J. (1999). "Mechanisms for pro matrix metalloproteinase activation." APMIS 107(1): 38-44.

Nagase, H., Meng, Q., Malinovskii, V., Huang, W., Chung, L., Bode, W., Maskos, K. and Brew, K. (1999). "Engineering of selective TIMPs." Ann N Y Acad Sci 878: 1-11. 
Nakada, M., Kita, D., Futami, K., Yamashita, J., Fujimoto, N., Sato, H. and Okada, Y. (2001). "Roles of membrane type 1 matrix metalloproteinase and tissue inhibitor of metalloproteinases 2 in invasion and dissemination of human malignant glioma." J Neurosurg 94(3): 464-73.

Nakada, M., Nakada, S., Demuth, T., Tran, N. L., Hoelzinger, D. B. and Berens, M. E. (2007). "Molecular targets of glioma invasion." Cell Mol Life Sci 64(4): 458-78.

Nakagawa, T., Kubota, T., Kabuto, M., Sato, K., Kawano, H., Hayakawa, T \& Okada, Y. (1994). "Production of matrix metalloproteinases and tissue inhibitor of metalloproteinases-1 by human brain tumors." J Neurosurg $81:$ 69-77

Novak, U., Stylli, S. S., Kaye, A. H. and Lepperdinger, G. (1999). "Hyaluronidase-2 overexpression accelerates intracerebral but not subcutaneous tumor formation of murine astrocytoma cells." Cancer Res 59(24): 6246-50.

Pagenstecher, A., Wussler, E. M., Opdenakker, G., Volk, B. and Campbell, I. L. (2001). "Distinct expression patterns and levels of enzymatic activity of matrix metalloproteinases and their inhibitors in primary brain tumors." J Neuropathol Exp Neurol 60(6): 598-612.

Pall, T., Gad, A., Kasak, L., Drews, M., Stromblad, S. and Kogerman, P. (2004). "Recombinant CD44-HABD is a novel and potent direct angiogenesis inhibitor enforcing endothelial cell-specific growth inhibition independently of hyaluronic acid binding." Oncogene 23(47): 7874-81.

Park, J. B., Kwak, H. J. and Lee, S. H. (2008). "Role of hyaluronan in glioma invasion." Cell Adh Migr 2(3): 202-7.

Paszek, M. J., Zahir, N., Johnson, K. R., Lakins, J. N., Rozenberg, G. I., Gefen, A., ReinhartKing, C. A., Margulies, S. S., Dembo, M., Boettiger, D., Hammer, D. A. and Weaver, V. M. (2005). "Tensional homeostasis and the malignant phenotype." Cancer Cell 8(3): 241-54.

Provenzano, P. P., Inman, D. R., Eliceiri, K. W., Beggs, H. E. and Keely, P. J. (2008). "Mammary epithelial-specific disruption of focal adhesion kinase retards tumor formation and metastasis in a transgenic mouse model of human breast cancer." Am J Pathol 173(5): 1551-65.

Quirico-Santos, T., Fonseca, C. O. and Lagrota-Candido, J. (2010). "Brain sweet brain: importance of sugars for the cerebral microenvironment and tumor development." Arq Neuropsiquiatr 68(5): 799-803.

Raithatha, S. A., Muzik, H., Rewcastle, N. B., Johnston, R. N., Edwards, D. R. and Forsyth, P. A. (2000). "Localization of gelatinase-A and gelatinase-B mRNA and protein in human gliomas." Neuro Oncol 2(3): 145-50.

Roijani M.V., Wiranowska, M., \& Roijani A.M.. (2011). “Matrix Metalloproteinases and Their Inhibitors-Friend or Foe" in Tumor Microenvironment (ed Dietmar W. Siemann) J. Wiley and Sons, Ltd.

Ranuncolo, S. M., Ladeda, V., Specterman, S., Varela, M., Lastiri, J., Morandi, A., Matos, E., Bal de Kier Joffe, E., Puricelli, L. and Pallotta, M. G. (2002). "CD44 expression in human gliomas." J Surg Oncol 79(1): 30-5; discussion 35-6.

Rao, J. S. (2003). "Molecular mechanisms of glioma invasiveness: the role of proteases." Nat Rev Cancer 3(7): 489-501.

Rao, J. S., Steck, P. A., Tofilon, P., Boyd, D., Ali-Osman, F., Stetler-Stevenson, W. G., Liotta, L. A. and Sawaya, R. (1994). "Role of plasminogen activator and of 92-KDa type IV 
collagenase in glioblastoma invasion using an in vitro matrigel model." J Neurooncol 18(2): 129-38.

Ricci-Vitiani, L., Pallini, R., Biffoni, M., Todaro, M., Invernici, G., Cenci, T., Maira, G., Parati, E. A., Stassi, G., Larocca, L. M. and De Maria, R. (2010). "Tumour vascularization via endothelial differentiation of glioblastoma stem-like cells." Nature 468(7325): 824-8.

Ricciardelli, C., Sakko, A. J., Ween, M. P., Russell, D. L. and Horsfall, D. J. (2009). "The biological role and regulation of versican levels in cancer." Cancer Metastasis Rev 28(1-2): 233-45.

Rivera, S., Khrestchatisky, M., Kaczmarek, L., Rosenberg, G. A. and Jaworski, D. M. (2010). "Metzincin proteases and their inhibitors: foes or friends in nervous system physiology?" J Neurosci 30(46): 15337-57.

Rooney, P., Kumar, S., Ponting, J. and Wang, M. (1995). "The role of hyaluronan in tumour neovascularization (review)." Int J Cancer 60(5): 632-6.

Rosen, J. M. and Jordan, C. T. (2009). "The increasing complexity of the cancer stem cell paradigm." Science 324(5935): 1670-3.

Roy, R., Yang, J. and Moses, M. A. (2009). "Matrix metalloproteinases as novel biomarkers and potential therapeutic targets in human cancer." J Clin Oncol 27(31): 5287-97.

Rubenstein, J. L., Kim, J., Ozawa, T., Zhang, M., Westphal, M., Deen, D. F. and Shuman, M. A. (2000). "Anti-VEGF antibody treatment of glioblastoma prolongs survival but results in increased vascular cooption." Neoplasia 2(4): 306-14.

Sameshima, T., Nabeshima, K., Toole, B. P., Yokogami, K., Okada, Y., Goya, T., Koono, M. and Wakisaka, S. (2000). "Expression of emmprin (CD147), a cell surface inducer of matrix metalloproteinases, in normal human brain and gliomas." Int J Cancer 88(1): 21-7.

Sanz, L., Feijoo, M., Blanco, B., Serrano, A. and Alvarez-Vallina, L. (2003). "Generation of non-permissive basement membranes by anti-laminin antibody fragments produced by matrix-embedded gene-modified cells." Cancer Immunol Immunother 52(10): 643-7.

Sarkar, S., Nuttall, R. K., Liu, S., Edwards, D. R. and Yong, V. W. (2006). "Tenascin-C stimulates glioma cell invasion through matrix metalloproteinase-12." Cancer Res 66(24): 11771-80.

Sawaya, R., Go, Y., Kyritisis, A. P., Uhm, J., Venkaiah, B., Mohanam, S., Gokaslan, Z. L. and Rao, J. S. (1998). "Elevated levels of Mr 92,000 type IV collagenase during tumor growth in vivo." Biochem Biophys Res Commun 251(2): 632-6.

Scadden, D. T. (2006). "The stem-cell niche as an entity of action." Nature 441(7097): 1075-9.

Schrappe, M., Klier, F. G., Spiro, R. C., Waltz, T. A., Reisfeld, R. A. and Gladson, C. L. (1991). "Correlation of chondroitin sulfate proteoglycan expression on proliferating brain capillary endothelial cells with the malignant phenotype of astroglial cells." Cancer Res 51(18): 4986-93.

Shen, Q., Goderie, S. K., Jin, L., Karanth, N., Sun, Y., Abramova, N., Vincent, P., Pumiglia, K. and Temple, S. (2004). "Endothelial cells stimulate self-renewal and expand neurogenesis of neural stem cells." Science 304(5675): 1338-40.

Sim, H., Hu, B. and Viapiano, M. S. (2009). "Reduced expression of the hyaluronan and proteoglycan link proteins in malignant gliomas." J Biol Chem 284(39): 26547-56.

Sorensen, A. G., Batchelor, T. T., Zhang, W. T., Chen, P. J., Yeo, P., Wang, M., Jennings, D., Wen, P. Y., Lahdenranta, J., Ancukiewicz, M., di Tomaso, E., Duda, D. G. and Jain, R. K. (2009). "A "vascular normalization index" as potential mechanistic biomarker 
to predict survival after a single dose of cediranib in recurrent glioblastoma patients." Cancer Res 69(13): 5296-300.

Stallcup, W. B. and Huang, F. J. (2008). "A role for the NG2 proteoglycan in glioma progression." Cell Adh Migr 2(3): 192-201.

Stojic, J., Hagemann, C., Haas, S., Herbold, C., Kuhnel, S., Gerngras, S., Roggendorf, W., Roosen, K. and Vince, G. H. (2008). "Expression of matrix metalloproteinases MMP1, MMP-11 and MMP-19 is correlated with the WHO-grading of human malignant gliomas." Neurosci Res 60(1): 40-9.

Stylli, S. S., Kaye, A. H. and Lock, P. (2008). "Invadopodia: at the cutting edge of tumour invasion." J Clin Neurosci 15(7): 725-37.

Sykova, E. (2002). "Plasticity of extracellular space". In The Neuronal Environment. Walz W.Ed: Humana Press Inc. pp 57-81

Takahashi, M., Fukami, S., Iwata, N., Inoue, K., Itohara, S., Itoh, H., Haraoka, J. and Saido, T. (2002). "In vivo glioma growth requires host-derived matrix metalloproteinase 2 for maintenance of angioarchitecture." Pharmacol Res 46(2): 155-63.

Takano, S., Mashiko, R., Osuka, S., Ishikawa, E., Ohneda, O. and Matsumura, A. (2010). "Detection of failure of bevacizumab treatment for malignant glioma based on urinary matrix metalloproteinase activity." Brain Tumor Pathol 27(2): 89-94.

Tammi, R., MacCallum, D., Hascall, V. C., Pienimaki, J. P., Hyttinen, M. and Tammi, M. (1998). "Hyaluronan bound to CD44 on keratinocytes is displaced by hyaluronan decasaccharides and not hexasaccharides." J Biol Chem 273(44): 28878-88.

Theocharis, A.D., Skandalis S.S., Tzanakakis, G.N., Karamanos, N.K.. (2010). "Proteoglycans in health and disease: novel roles for proteoglycans in malignancy and their pharmacological targeting". FASEB J. 277 (19):3904-23.

Thomas, T. W. and DiMilla, P. A. (2000). "Spreading and motility of human glioblastoma cells on sheets of silicone rubber depend on substratum compliance." Med Biol Eng Comput 38(3): 360-70.

Toole, B. P. and Slomiany, M. G. (2008). "Hyaluronan, CD44 and Emmprin: partners in cancer cell chemoresistance." Drug Resist Updat 11(3): 110-21.

Tysnes, B. B., Mahesparan, R., Thorsen, F., Haugland, H. K., Porwol, T., Enger, P. O., LundJohansen, M. and Bjerkvig, R. (1999). "Laminin expression by glial fibrillary acidic protein positive cells in human gliomas." Int J Dev Neurosci 17(5-6): 531-9.

Uhm, J. H., Dooley, N. P., Villemure, J. G. and Yong, V. W. (1996). "Glioma invasion in vitro: regulation by matrix metalloprotease-2 and protein kinase C." Clin Exp Metastasis 14(5): 421-33.

Ulrich, T. A., de Juan Pardo, E. M. and Kumar, S. (2009). "The mechanical rigidity of the extracellular matrix regulates the structure, motility, and proliferation of glioma cells." Cancer Res 69(10): 4167-74.

VanMeter, T. E., Rooprai, H. K., Kibble, M. M., Fillmore, H. L., Broaddus, W. C. and Pilkington, G. J. (2001). "The role of matrix metalloproteinase genes in glioma invasion: co-dependent and interactive proteolysis." J Neurooncol 53(2): 213-35.

Verhaak, R. G., Hoadley, K. A., Purdom, E., Wang, V., Qi, Y., Wilkerson, M. D., Miller, C. R., Ding, L., Golub, T., Mesirov, J. P., Alexe, G., Lawrence, M., O'Kelly, M., Tamayo, P., Weir, B. A., Gabriel, S., Winckler, W., Gupta, S., Jakkula, L., Feiler, H. S., Hodgson, J. G., James, C. D., Sarkaria, J. N., Brennan, C., Kahn, A., Spellman, P. T., Wilson, R. K., Speed, T. P., Gray, J. W., Meyerson, M., Getz, G., Perou, C. M. and Hayes, D. N. 
(2010). "Integrated genomic analysis identifies clinically relevant subtypes of glioblastoma characterized by abnormalities in PDGFRA, IDH1, EGFR, and NF1." Cancer Cell 17(1): 98-110.

Viapiano, M. S. and Matthews, R. T. (2006). "From barriers to bridges: chondroitin sulfate proteoglycans in neuropathology." Trends Mol Med 12(10): 488-96.

Wang, M., Wang, T., Liu, S., Yoshida, D. and Teramoto, A. (2003). "The expression of matrix metalloproteinase-2 and -9 in human gliomas of different pathological grades." Brain Tumor Pathol 20(2): 65-72.

Wang, R., Chadalavada, K., Wilshire, J., Kowalik, U., Hovinga, K. E., Geber, A., Fligelman, B., Leversha, M., Brennan, C. and Tabar, V. (2010). "Glioblastoma stem-like cells give rise to tumour endothelium." Nature 468(7325): 829-33.

Wiranowska, M., Ladd, S., Moscinski, L. C., Hill, B., Haller, E., Mikecz, K. and Plaas, A. (2010). "Modulation of hyaluronan production by CD44 positive glioma cells." Int J Cancer 127(3): 532-42.

Wiranowska, M., Ladd, S., Smith, S. R. and Gottschall, P. E. (2006). "CD44 adhesion molecule and neuro-glial proteoglycan NG2 as invasive markers of glioma." Brain Cell Biol 35(2-3): 159-72.

Wiranowska, M. and Naidu, A. K. (1994). "Interferon effect on glycosaminoglycans in mouse glioma in vitro." J Neurooncol 18(1): 9-17.

Wiranowska, M. and Plaas, A . (2008). "Cytokines and Extracellular Matrix Remodeling in the Central Nervous System". In: Neuroimmune Biology ( I.Berczi, and A. Szentivanyi, eds.), vol. 6, Cytokines and the Brain, Elsevier B.V. Science.

Wiranowska, M., Rojiani, A. M., Gottschall, P. E., Moscinski, L. C., Johnson, J. and Saporta, S. (2000). "CD44 expression and MMP-2 secretion by mouse glioma cells: effect of interferon and anti-CD44 antibody." Anticancer Res 20(6B): 4301-6.

Wiranowska, M., Tresser, N. and Saporta, S. (1998). "The effect of interferon and anti-CD44 antibody on mouse glioma invasiveness in vitro." Anticancer Res 18(5A): 3331-8.

Xu, Y., Stamenkovic, I. and Yu, Q. (2010). "CD44 attenuates activation of the hippo signaling pathway and is a prime therapeutic target for glioblastoma." Cancer Res 70(6): 2455-64.

Yamamoto, M., Mohanam, S., Sawaya, R., Fuller, G. N., Seiki, M., Sato, H., Gokaslan, Z. L., Liotta, L. A., Nicolson, G. L. and Rao, J. S. (1996). "Differential expression of membrane-type matrix metalloproteinase and its correlation with gelatinase A activation in human malignant brain tumors in vivo and in vitro." Cancer Res 56(2): 384-92.

Yamamoto, M., Sawaya, R., Mohanam, S., Bindal, A. K., Bruner, J. M., Oka, K., Rao, V. H., Tomonaga, M., Nicolson, G. L. and Rao, J. S. (1994). "Expression and localization of urokinase-type plasminogen activator in human astrocytomas in vivo." Cancer Res 54(14): 3656-61.

Yang, P., Baker, K. A. and Hagg, T. (2006). "The ADAMs family: coordinators of nervous system development, plasticity and repair." Prog Neurobiol 79(2): 73-94.

Yue, W. Y. and Chen, Z. P. (2005). "Does vasculogenic mimicry exist in astrocytoma?" J Histochem Cytochem 53(8): 997-1002.

Zagzag, D., Friedlander, D. R., Miller, D. C., Dosik, J., Cangiarella, J., Kostianovsky, M., Cohen, H., Grumet, M. and Greco, M. A. (1995). "Tenascin expression in astrocytomas correlates with angiogenesis." Cancer Res 55(4): 907-14. 
Zhang, B., Gu, F., She, C., Guo, H., Li, W., Niu, R., Fu, L., Zhang, N. and Ma, Y. (2009). "Reduction of Akt2 inhibits migration and invasion of glioma cells." Int J Cancer 125(3): 585-95.

Zhang S., Zhang, D., \& Sun, B. (2007). "Vascular mimicry: Current status and future prospects." Cancer Letters, vol. 254, pp157-164. 


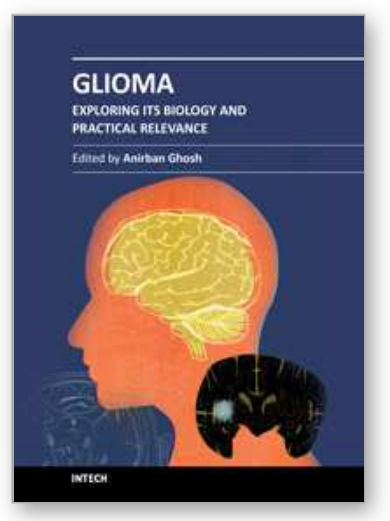

\author{
Glioma - Exploring Its Biology and Practical Relevance \\ Edited by Dr. Anirban Ghosh
}

ISBN 978-953-307-379-8

Hard cover, 486 pages

Publisher InTech

Published online 02, November, 2011

Published in print edition November, 2011

The tittle 'Glioma - Exploring Its Biology and Practical Relevance' is indicative of its content. This volume contains 21 chapters basically intended to explore glioma biology and discussing the experimental model systems for the purpose. It is hoped that the present volume will provide supportive and relevant awareness and understanding on the fundamental advances of the subject to the professionals from any sphere interested about glioma.

\title{
How to reference
}

In order to correctly reference this scholarly work, feel free to copy and paste the following:

Marzenna Wiranowska and Mumtaz V. Rojiani (2011). Extracellular Matrix Microenvironment in Glioma Progression, Glioma - Exploring Its Biology and Practical Relevance, Dr. Anirban Ghosh (Ed.), ISBN: 978-953307-379-8, InTech, Available from: http://www.intechopen.com/books/glioma-exploring-its-biology-andpractical-relevance/extracellular-matrix-microenvironment-in-glioma-progression

\section{INTECH}

open science | open minds

\section{InTech Europe}

University Campus STeP Ri

Slavka Krautzeka 83/A

51000 Rijeka, Croatia

Phone: +385 (51) 770447

Fax: +385 (51) 686166

www.intechopen.com

\section{InTech China}

Unit 405, Office Block, Hotel Equatorial Shanghai

No.65, Yan An Road (West), Shanghai, 200040, China

中国上海市延安西路65号上海国际贵都大饭店办公楼 405 单元

Phone: +86-21-62489820

Fax: +86-21-62489821 
(C) 2011 The Author(s). Licensee IntechOpen. This is an open access article distributed under the terms of the Creative Commons Attribution 3.0 License, which permits unrestricted use, distribution, and reproduction in any medium, provided the original work is properly cited. 